\title{
Do blind people share the tall-man stereotype?
}

\author{
Michal Mikolaj Stefanczyk ${ }^{1}$ (1) $\cdot$ Natalia Wernecka ${ }^{1} \cdot$ Piotr Sorokowski $^{1} \cdot$ Agnieszka Sorokowska $^{1,2}$
}

Published online: 28 March 2019

(C) The Author(s) 2019

\begin{abstract}
The stereotype of a tall man has been reported in numerous studies. High stature is commonly associated with advantages such as leadership skills, wealth, intelligence or social status, and actual differences between the short and the tall men were indeed found for these traits, mainly in favor of the tall men. It is not certain, however, whether the height-related effects are biologically determined or if they result from socially-driven mechanisms. In this study we wanted to explore whether congenitally blind individuals, who are unable to perceive other people's stature through the most salient, visual channel, share the positive, heightrelated stereotype. Thirty-four congenitally blind and forty-three sighted men and women rated four positive characteristics of a tall or a short man. It was found that none of the traits assigned to the tall man by the sighted people was assigned to this person by the blind individuals. In the congenitally blind group, no differences between the assessments of the tall and the short man were revealed. We discuss our findings in the context of social perception and stereotypes research.
\end{abstract}

Keywords Blindness $\cdot$ Visual impairment $\cdot$ Stature $\cdot$ Tall man stereotype $\cdot$ Social perception

\section{Introduction}

Numerous studies show that male tallness is associated with many positive traits. Stature was found to be positively correlated with earnings and socio-economic status (i.e., Cinnirella and Winter 2009; Judge and Cable 2004; Turrell 2002; Dannenmaier and Thumin 1964; Case and Paxson 2008) and independence and dominance tend to be positively associated with tall rather than short height (Re et al. 2013). There is also a significant positive correlation between height and intelligence (Teasdale et al. 1991; Kanazawa and

Michal Mikolaj Stefanczyk

michal.m.stefanczyk@gmail.com

Natalia Wernecka

nwernecka@gmail.com

Piotr Sorokowski

sorokowskipiotr@yahoo.co.uk

Agnieszka Sorokowska

sorokowska@gmail.com

1 Institute of Psychology, University of Wroclaw, ul. Dawida 1, 50-527 Wroclaw, Poland

2 Department of Psychotherapy and Psychosomatic Medicine, TU Dresden, Fetscherstr. 74, 01307 Dresden, Germany
Reyniers 2009; Marioni et al. 2014; Beauchamp et al. 2011; Taki et al. 2012; Tanner 1966), and impaired cognitive abilities are more common among shorter than taller elderly men (Abbott et al. 1998). Further, shorter people tend to have fewer academic achievements (Cavelaars et al. 2001; Wheeler et al. 2004). Moreover, tall men usually occupy more prominent positions at work (Case and Paxson 2008; Gawley et al. 2009; Egolf and Corder 1991) and are more efficient in a position of power (namely, they are better able to maintain control over other people, tend to behave more authoritatively and are perceived as more competent in key positions; Stulp et al. 2012).

Tall men experience many advantages in their lives, and high stature is associated with a very positive social perception. For example, tall men are more likely to win political elections (McCann 2001), since they are considered to communicate better and to have more leadership skills than shorter candidates (Persico et al. 2004; Stulp et al. 2013). What is more, height of capable leaders is estimated as greater than stature of those who do not perform well in the position of power (Sorokowski et al. 2014). Those who achieved success, e.g., in political elections, are perceived as taller in comparison with the estimations of their height before the victory, while losers "shrink" in the eyes of the others (Higham and Carment 1992; Sorokowski 2010). The tendency to choose taller candidates in the elections due to their presumably greater 
leadership skills intensifies during the wartime, because of perceived associations between tall height, independence and dominance (Re et al. 2013). Furthermore, tall men are perceived as having a superior status (Dannenmaier and Thumin 1964; Lechelt 1975). For example, an unknown man, who was introduced to the audience as a student, was rated as much shorter than the same man, but presented as a psychology professor (Wilson et al. 1968). What is more, people are likely to associate superior stature in men with many other favorable characteristics, such as greater physical attractiveness, health, competence and higher morale (Pierce 1996; Lester and Sheehan 1980; Agerström 2014). Kurtz (1969) found that people believe that taller height results in greater efficiency at work.

Certain studies suggest that the link between tallness and positive traits such as intelligence, wealth, leadership skills and social status is biologically-driven. According to Persico et al. (2004), tall men, thanks to their height, could outdo rivals in the struggle over resources in our evolutionary past; further, high stature could signalize genetic resistance towards illness or shortage of resources, while lower stature might result from infectious diseases or malnutrition over the course of development (Beard and Blaser 2002; Kopacova et al. 2014; Hwang et al. 2013). Thus, tall height as a trait could have been favored in the natural selection. The positive aspects of being tall derive also from an association between height and cognitive abilities (Case and Paxson 2008), which are rewarded both in terms of labor market desirability and interpersonal attractiveness. Indeed, tall men are preferred as mates - they tend to have more partners (Nettle 2002; Sear 2006), marry earlier (Murray 1997), remarry more often (Mueller and Mazur 2001), and get more responses for their lonely hearts advertisements (Lynn and Shurgot 1984). Since they are able to enter a new relationship relatively quicker, they tend to be less jealous of their romantic partner (Buunk et al. 2008). They also have a lower risk of being childless (Pawlowski et al. 2000).

Most studies discussed in previous sections of this introduction show that the male tallness is associated with many positive features; however, some aspects of this positive image do not necessarily result from actual characteristics of tall men. It is possible that the positive social perception of height might be mediated by the way tall people are perceived by others (Feldman 1975). Some mechanisms shown in classical social science experiments are likely to explain such a possibility. These include stereotypes, which later influence the perception of a tall/short person through phenomena such as the self-fulfilling prophecies and Pygmalion effect (Rosenthal 1973; Rosenthal and Jacobson 1968), or Golem effect (Babad et al. 1982). A stereotype is a fixed, over generalized belief about a particular group or class of people (Cardwell 1999). It is automatically activated when an individual encounters or gains knowledge about certain features associated with it (Bargh et al. 1996). The positive stereotype of tallness and preference for tall height in men could be shaped and transferred culturally. In such a case, the tall-man stereotype would likely exert an influence on a preference for tall height in men.

Nevertheless, the tallness stereotype may not be as intrinsic and universal as it seems - this conclusion was not supported by the results of studies conducted in traditional societies (Undurraga et al. 2012; Sorokowski and Sorokowska 2012; Sorokowski et al. 2012). Members of traditional societies, such as foraging-farming Tsimane' from Amazonia, attributed positive traits to taller children, but not adults (Undurraga et al. 2012), the Yali tribe of Papua favor tallness in men to a far lesser extent than the Western societies do (Sorokowski and Sorokowska 2012), and in a semi-nomad population of Himba in Namibia the largest proportion of the participants preferred a partner with a height equal to one's own (Sorokowski et al. 2012).

It is thus very interesting to investigate whether the positive perception of tall men results from some biologicallydetermined characteristics associated with tallness, or whether it rather results from socially-driven mechanisms. Biologically-driven preferences should be independent from the daily experience, necessary to form (Rosch and Lloyd 1978) or activate certain schemas and stereotypes (Higgins 1996). This issue could be examined among people, for whom the development and acquisition of height stereotype can be greatly impeded even within a culture, where such a stereotype is very strong. Potentially, this group can comprise blind people, who lack visual input, a significant source of information in terms of social perception (Allison et al. 2000). The blind individuals, who cannot perceive the height visually, may not associate the previously discussed positive traits with tall stature. On the other hand, a preference for waist-to-hip ratio of 0.7 , an indicator of good health and fertility in women, was observed independent of visual status (Karremans et al. 2010). This proves that the universal, biologically determined preferences can be also observed among the blind individuals.

In the current research, we aimed to examine whether blind people, who live in a culture with a strong tall-man stereotype, but are not able to see the stature of men and therefore associate it with particular, positive traits, share the positive tallness stereotype. Our goal was to compare preferences of congenitally blind and sighted individuals in the area of interpersonal attractiveness, namely in its four aspects - perceived intelligence, wealth, leadership skills and social-economic status. It was hypothesized that congenitally blind people have not developed the tall man stereotype, having no chance to ever receive visual stimuli and assimilate them into personal, however commonly shared schemas (Zou et al. 2009). 


\section{Materials and Methods}

\section{Participants}

The participants were 77 men and women, aged from 16 to 65 $(M=36.04, S D=12.86)$. They were recruited for a multistage research concerning sensory compensation in blindness. All participants were tested individually in the university's laboratory. They were remunerated for the participation. The sighted group consisted of 43 people ( 24 women and 19 men, aged from 20 to 65 ), and the blind group comprised 34 congenitally blind people (17 women and 17 men, aged from 16 to 64).

\section{Procedure}

First, the participants were questioned about their visual status, age and gender. Then, a short story was read to them aloud by an experimenter. It described a non-existing person called Thomas and included a brief note about the character's height: in one version, read to the first half of the participants, he was $166 \mathrm{~cm}$ ( $\sim 65.4$ in.) tall, in the second version he was $190 \mathrm{~cm}$ ( 74.8 in.) tall. These numbers reflect the second standard deviation of the eighteen-years-old males' height in Poland (Kułaga et al. 2009). After hearing the story, the participants were asked to assess on a Likert 1-5 scale, where " 1 " meant "definitely not" and " 5 " meant "definitely yes", to what extent Thomas was intelligent, wealthy, a good leader and how high his social status was.

\section{Results}

All analyses were performed by the means of Statistica Software, version 13.1. The data from the current study are available under a link: https://osf.io/p8ydf/?view_only= 899cec6a43ac4e36a4279494fof 22c41.

To verify whether the groups differed in evaluation of Thomas depending on the information about his height, we performed analysis of variance (ANOVA) with pairwise comparisons. For each of the traits included as dependent variables we conducted a separate analysis of variance (ANOVA) with participants' visual status (sighted vs. blind people) and the version of the story they were told ('short Thomas' vs. 'tall Thomas') included as independent variables. For all characteristics analyzed together, tested model revealed a significant interaction between participants' visual status and the story they heard, $F_{4,70}=2.76, p<.03, \eta^{2}=.14$, therefore we explored every evaluated aspect separately.

Intelligence In terms of evaluated intelligence, the observed effect was on a trend level $\left(F_{1,73}=3.15, p<.09, \eta^{2}=.04\right)$. Post-hoc tests indicated that within the group of sighted participants, 'tall Thomas' was indeed assessed as more intelligent $(M=3.62 \pm .67)$ than 'short Thomas' $(M=3.09$ $\pm .81 ; p=.03)$, while no such differences were found in the blind group ( $M=3.2 \pm .94$ and $M=3.32 \pm .75$ for 'tall Thomas' and 'short Thomas', respectively; $p>.05$ ).

Wealth In the case of wealth, we found a significant interaction between the visual status and the version of the story $\left(F_{1,73}=55,811, p<.03, \eta^{2}=.07\right)$. Post-hoc tests showed that the sighted, but not the blind participants, rated 'tall Thomas' as wealthier $(M=3.62 \pm .74)$ than 'short Thomas' $(M=2.95$ $\pm .95 ; p=.006)$, whereas the blind participants did not differentiate between 'tall Thomas' $(M=3.2 \pm .68)$ and 'short Thomas' $(M=3.37 \pm .6 ; p>.05)$.

Leadership Skills In the analysis of leadership skills, we found a significant interaction effect of visual status and Thomas' height $\left(F_{1,73}=77,346, p<.007, \eta^{2}=.1\right)$. The post-hoc tests revealed that in the sighted group 'tall Thomas' was estimated as a better leader $(M=3.57 \pm .68)$ than 'short Thomas' $(M=$ $2.73 \pm 1.24 ; p=.01)$, and that 'tall Thomas' was evaluated more favorably among the sighted than among the blind participants $(M=2.4 \pm 1.12 ; p=.002)$. The latter did not distinguish between 'short Thomas' $(M=2.95 \pm 1.22)$ and 'tall Thomas' $(M=2.4 \pm 1.12 ; p>.05)$.

Social Status Similar results were obtained in the case of social status $\left(F_{1,73}=8.19, p<.006, \eta^{2}=.1\right)$. Post-hoc tests showed that the sighted people ranked social status of 'tall Thomas' higher $(M=3.57 \pm .67)$ than of 'short Thomas' $(M=3 \pm .76 ; p=.01)$. The status of 'Tall Thomas' was higher among the sighted than among the blind subjects $(M=2.93 \pm .59 ; p=.01)$. Once again, in the assessments of the blind people, there were no significant discrepancies in assessments of the social status of 'tall Thomas' and 'short Thomas' $(M=3.32 \pm .82 ; p>.05)$.

No main effects of either the sight status or the version of the story were observed in any of the rated traits.

\section{Discussion}

The results of our research indicate that blind people do not associate tallness with a man's interpersonal abilities, unlike the sighted participants, among whom we observed a pronounced, positive, height-related stereotype in the case of perceived intelligence, wealth, leadership skills and status. These findings are consistent with our hypothesis and suggest that seeing might be necessary to develop the positive stereotype of high male stature. Relatedly, the preference for tall men seems not to be a biological inclination, but rather a learned association. This explanation is consistent with the findings in traditional societies such as Tsimane or Yali (Undurraga et al. 2012; Sorokowski et al. 2012; Sorokowski and Sorokowska 
2012), where the tall-man stereotype was found to be absent or developed to a much lesser extent than in Western cultures.

No preference for tall height in men in congenitally blind people suggests that it could be necessary to have an individual contact with certain models of attractiveness to share common preferences that are not, however, biologically-driven. As mentioned before, null effects of height on attractiveness were shown also in traditional societies with little access to Western culture (Undurraga et al. 2012; Sorokowski and Sorokowska 2012; Sorokowski et al. 2012). The results of previous research were mostly explained in terms of local ecological conditions, that did not necessarily favor tallness in males. Our data suggests that individual experience with popular culture that promotes the height stereotype could be another important determinant of tall height preferences. Sighted people in our research evaluated a person differently based on a single piece of information regarding this person's height. They assessed various characteristics of a man who was tall as significantly more positive than traits of a short man. The findings fit nicely to the outcomes observed in previous research. Tall men are rated as being better leaders (Blaker et al. 2013), as having superior social status (Lechelt 1975), and as more intelligent and employable (Kurtz 1969) than short men. Moreover, individuals depict nation leaders as taller than average citizens (Murray and Schmitz 2011). However, it seems that these positive traits are not intrinsically associated with male tallness, as blind people did not attribute them to the "tall Thomas" in our study.

Our data suggest that at least some assets of tall men might be developed as a consequence of positive stereotypes. Such effect could be based on Rosenthal's Pygmalion effect (Rosenthal and Jacobson 1968), especially in light of Persico, Postlewaite and Silverman's findings (Persico et al. 2004). According to these authors, the advantages of high stature are claimed not by tall men in general, but those who were already tall as the teenagers. Possibly, based on the tall height stereotype, they were treated better than their shorter peers from the beginning, so they acquired greater social skills, unlike those who grew later and could have experienced disadvantages due to their height. Such a mechanism could explain at least some actual differences in psychological characteristics of short and tall men, such as increased dominance (Re et al. 2013) or intelligence (Teasdale et al. 1991; Kanazawa and Reyniers 2009; Marioni et al. 2014; Beauchamp et al. 2011; Taki et al. 2012; Tanner 1966) of the latter. However, our study shows that the tall-man stereotype is not strong enough to exert influence on all members of a society, as we did not observe it among people who lack the visual input.

On the other hand, Higgins' theory of acquiring a stereotype (Higgins 1996) suggests another possibility. According to the author, a stereotype needs to be not only developed, but it has to be also accessible and applicable in a given situation to be 'activated' and have impact on one's perception. Thus, it is possible that the blind people do share the preference for tall men, but that the schema responsible for that was not incited in our experiment. Understanding the height information given in centimeters, specific units of measurements, might depend on calibration during one's individual visual experience. Blind people may not link the exact height (presented as a number) with tallness or shortness, because they do not determine physical relations between objects or measure them with standardized units as often as sighted people. Therefore, centimeters may not appeal to blind people's imagination and could leave the stereotype inactivated. However, to address this problem, we called a sub-sample of our participants (20 people) to ask whether they knew exactly how tall they were (in centimeters). Out of 20 people we talked to, only one person was unable to provide an exact measure. We can thus say that blind people can understand information about a person's absolute height and conclude that he/she is relatively tall or short as compared to their own stature (women: between 154 and 175, $M=$ $165.23 \pm 5.44$; men: between 160 and $187, M=172 \pm 8.40)$. Consequently, they could classify "Thomas" they heard about as tall or short. Two recent studies conducted in a mixed group of early- and late-blind participants showed that, based on vocal cues, blind people are able to assess who of the two speakers is taller (Pisanski et al. 2016, 2017), thus the relative assessments of height are definitely possible independent of visual status. Nevertheless, in future research on height stereotypes, the information in centimeters should rather be amended by an expression 'distinctively tall' or 'explicitly short'.

What also seems important to mention is the size of our sample. It can be considered a limitation to our study, as 34 blind participants may be considered as not a big enough sample; however, low sample sizes are rather ordinary in studies concerning visually impaired people. Congenitally blind people with no light perception are a rare group that can be extraordinarily difficult to find and recruit for scientific research. In comparison with previous studies, our sample can even be considered large (see for instance, 8 early-blind people in Cuevas et al. 2010; 7 early-blind individuals in Jiang et al. 2016; 10 early-blind people in Dormal et al. 2016). Nevertheless, further studies addressing the issue of tallness stereotypes should take that into account and focus on obtaining larger samples of participants.

In summary, this is one of the first studies concerning social evaluations made by blind and sighted people in the context of physique-related stereotypes. Except for the findings by Karremans et al. (2010) about the similarity of the waist-tohip ratio preferences in blind and sighted individuals, we do not know much about the associations between visual impairment and social preferences. Further studies on this topic are suggested, taking into account the suppositions made in this article. For instance, blind people can be categorized as lateblind and early blind. "Early blindness" applies to those individuals who lost their sight before the age of 2 , that is, before 
the completion of visual development (Wiesel 1982). Earlyand late-blind groups were shown to differ in terms of, e.g., sharpness of listening skills (Gougoux et al. 2004) or accuracy of tactile picture identification (Heller 1989). This creates a possibility to analyze whether the time of sight loss has an impact on acquiring and sharing the height stereotype. Moreover, since our study implies that blind people do not share the stereotype of a tall man, future research may focus on finding other allegedly universal and congenital convictions that are in fact not shared by the blind, thus making them rather learned, not innate.

Acknowledgements This research was supported by the Polish National Science Centre OPUS grant [\#2013/11/B/HS6/01522 to AS]. The authors thank all the participants for their cooperation and Anna Oleszkiewicz, Anna Trzepizur and Kacper Podgórniak for their help with data collection.

Funding This work was supported by the Polish National Science Centre OPUS grant [\#2013/11/B/HS6/01522] to Agnieszka Sorokowska. The sponsors had no involvement in study design; in the collection, analysis and interpretation of data; in the writing of the report; and in the decision to submit the article for publication.

Compliance with Ethical Standards This study was approved by the ethical board of the Institute of Psychology, University of Wroclaw and all procedures performed in it involving human participants were in accordance with the ethical standards of the institutional and/or national research committee and with the 1964 Helsinki declaration and its later amendments or comparable ethical standards.

Informed consent was obtained from all individual participants included in the study; the consent form was read aloud to the blind subjects.

Conflict of Interest Authors declare no conflict of interest. Authors had full control of all primary data and agree to allow the journal to review the data if requested.

Open Access This article is distributed under the terms of the Creative Commons Attribution 4.0 International License (http:// creativecommons.org/licenses/by/4.0/), which permits unrestricted use, distribution, and reproduction in any medium, provided you give appropriate credit to the original author(s) and the source, provide a link to the Creative Commons license, and indicate if changes were made.

\section{References}

Abbott, R. D., White, L. R., Ross, W., Petrovitch, H., Masaki, K. M., Snowdon, D. A., \& Curb, C. (1998). Height as a marker of childhood development and late-life cognitive function: The HonoluluAsia aging study. Pediatrics, 102(3), 602-609.

Agerström, J. (2014). Why does height matter in hiring? Journal of Behavioral and Experimental Economics, 52, 35-38.

Allison, T., Puce, A., \& McCarthy, G. (2000). Social perception from visual cues: Role of the STS region. Trends in Cognitive Sciences, 4(7), 267-278.

Babad, E. Y., Inbar, J., \& Rosenthal, R. (1982). Pygmalion, galatea, and the golem: investigations of biased and unbiased teachers. Journal of Educational Psychology, 74(4), 459-474.

Bargh, J. A., Chen, M., \& Burrows, L. (1996). Automaticity of social behavior: Direct effects of trait construct and stereotype activation on action. Journal of Personality and Social Psychology, 71(2), 230-244.
Beard, A. S., \& Blaser, M. J. (2002). The ecology of height: The effect of microbial transmission on human height. Perspectives in Biology and Medicine, 45(4), 475-498.

Beauchamp, J. P., Cesarini, D., Johannesson, M., Lindqvist, E., \& Apicella, C. (2011). On the sources of the height-intelligence correlation: New insights from a bivariate ACE model with assortative mating. Behavior Genetics, 4(2), 242-252.

Blaker, N. M., Rompa, I., Dessing, I. H., Vriend, A. F., Herschberg, C., \& Van Vugt, M. (2013). The height leadership advantage in men and women: Testing evolutionary psychology predictions about the perceptions of tall leaders. Group Processes \& Intergroup Relations, 16(1), 17-27.

Buunk, A. P., Park, J. H., Zurriaga, R., Klavina, L., \& Massar, K. (2008). Height predicts jealousy differently for men and women. Evolution and Human Behavior, 29, 133-139.

Cardwell, M. (1999). Dictionary of psychology. Chicago: Fitzroy Dearborn.

Case, A., \& Paxson, C. (2008). Stature and status: Height, ability, and labor market outcomes. Journal of Political Economy, 116(3), 499-532.

Cavelaars, A. E. J. M., Kunst, A. E., Geurts, J. J. M., Crialesi, R., Grötvedt, L., Helmert, U., et al. (2000). Persistent variations in average height between countries and between socio-economic groups: an overview of 10 European countries. Annals of Human Biology, 27(4), 407-421.

Cinnirella, F., \& Winter, J. K. (2009). Size matters! Body height and labor market discrimination: A cross-European analysis. CESifo Working Paper Series, 1-29.

Cuevas, I., Plaza, P., Rombaux, P., Collignon, O., De Volder, A. G., \& Renier, L. (2010). Do people who became blind early in life develop a better sense of smell? A psychophysical study. Journal of Visual Impairment \& Blindness, 104(6), 369-379.

Dannenmaier, W. D., \& Thumin, F. J. (1964). Authority status as a factor in perceptual distortion of sizes. The Journal of Social Psychology, 63(2), 361-365.

Dormal, V., Crollen, V., Baumans, C., Lepore, F., \& Collignon, O. (2016). Early but not late blindness leads to enhanced arithmetic and working memory abilities. Cortex, 83, 212-221.

Egolf, D. B., \& Corder, L. E. (1991). Height differences of low and high job status, female and male corporate employees. Sex Roles, 24(56), 365-373.

Feldman, S. D. (1975). The presentation of shortness in everyday lifeheight and heightism in American society: Toward a sociology of stature. Life Styles: Diversity in American Society, 427-442.

Gawley, T., Perks, T., \& Curtis, J. (2009). Height, gender, and authority status at work: Analyses for a national sample of Canadian workers. Sex Roles, 60, 208-222.

Gougoux, F., Lepore, F., Lassonde, M., Voss, P., Zatorre, R. J., \& Belin, P. (2004). Neuropsychology: Pitch discrimination in the early blind. Nature, 430(6997), 309.

Heller, M. A. (1989). Picture and pattern perception in the sighted and the blind: The advantage of the late blind. Perception, 18(3), 379-389.

Higgins, E. T. (1996). Knowledge activation: Accessibility, applicability, and salience. In E. T. Higgins \& A. W. Kruglansky (Eds.), Social psychology: Handbook of basic principles (pp. 133-168). New York: Guilford Press.

Higham, P. A., \& Carment, D. W. (1992). The rise and fall of politicians: The judged heights of Broadbent, Mulroney and Turner before and after the 1988 Canadian federal election. Canadian Journal of Behavioural Science, 24(3), 404-409.

Hwang, A. E., Mack, T. M., Hamilton, A. S., James Gauderman, W., Bernstein, L., Cockburn, M. G., Zadnick, J., Rand, K. A., Hopper, J. L., \& Cozen, W. (2013). Childhood infections and adult height in monozygotic twin pairs. American Journal of Epidemiology, 178(4), $551-558$.

Jiang, F., Stecker, G. C., Boynton, G. M., \& Fine, I. (2016). Early blindness results in developmental plasticity for auditory motion 
processing within auditory and occipital cortex. Frontiers in Human Neuroscience, 10, 324.

Judge, T. A., \& Cable, D. M. (2004). The effect of physical height on workplace success and income: Preliminary test of a theoretical model. Journal of Applied Psychology, 89(3), 428-441.

Kanazawa, S., \& Reyniers, D. J. (2009). The role of height in the sex difference in intelligence. The American Journal of Psychology, 122(4), 527-536.

Karremans, J. C., Frankenhuis, W. E., \& Arons, S. (2010). Blind men prefer a low waist-to-hip ratio. Evolution and Human Behavior, 31, $182-186$.

Kopacova, M., Koupil, I., Seifert, B., Fendrichova, M. S., Spirkova, J., Vorisek, V., Rejchrt, S., Douda, T., Tacheci, I., \& Bures, J. (2014). Blood pressure and stature in Helicobacter pylori positive and negative persons. World journal of gastroenterology: WJG, 20(19), 5625.

Kułaga, Z., Litwin, M., Zajączkowska, M. M., Wasilewska, A., Tkaczyk, M., Gurzkowska, B., Świąder, A., Różdżyńska, A., Napieralska, E., Grajda, A., Barwicka, K., \& Zespół Badawczy, O. L. A. F. (2009). Regionalne różnice parametrów antropometrycznych oraz ciśnienia tętniczego uczniów w wieku 7-18 lat. Problemy Higieny $i$ Epidemiologii, 90(1), 32-41.

Kurtz, D. L. (1969). Physical appearance and stature: Important variables in sales recruiting. The Personnel Journal, 48, 981-983.

Lechelt, E. C. (1975). Occupational affiliation and ratings of physical height and personal esteem. Psychological Reports, 36(3), 943-946.

Lester, D., \& Sheehan, D. (1980). Attitudes of supervisors toward short police officers. Psychological Reports, 47, 462.

Lynn, M., \& Shurgot, B. A. (1984). Responses to lonely hearts advertisements: Effects of reported physical attractiveness, physique, and coloration. Personality and Social Psychology Bulletin, 10(3), 349-357.

Marioni, R. E., Batty, G. D., Hayward, C., Kerr, S. M., Campbell, A., Hocking, L. J., Generation Scotland, Porteous, D. J., Visschr, P. M., \& Deary, I. J. (2014). Common genetic variants explain the majority of the correlation between height and intelligence: The generation Scotland study. Behavior Genetics, 44, 91-96.

McCann, S. J. H. (2001). Height, societal threat, and the victory margin in residential elections (1824-1992). Psychological Reports, 88, 741-742.

Mueller, U., \& Mazur, A. (2001). Evidence of unconstrained directional selection for male tallness. Behavioral Ecology and Sociobiology, 50(4), 302-311.

Murray, J. E. (1997). Standards of the present for people of the past: height, weight, and mortality among men of Amherst College, 1834-1949. The Journal of Economic History, 57(3), 585-606.

Murray, G. R., \& Schmitz, J. D. (2011). Caveman politics: Evolutionary leadership preferences and physical stature. Social Science Quarterly, 92(5), 1215-1235.

Nettle, D. (2002). Height and reproductive success in a cohort of British men. Human Nature, 13(4), 473-491.

Pawlowski, B., Dunbar, R. I., \& Lipowicz, A. (2000). Evolutionary fitness: Tall men have more reproductive success. Nature, 403(6766), 156.

Persico, N., Postlewaite, A., \& Silverman, D. (2004). The effect of adolescent experience on labor market outcomes: The case of height. Journal of Political Economy, 112(5), 1019-1053.

Pierce, C. A. (1996). Body height and romantic attraction: A metaanalytic test of the male-taller norm. Social Behavior and Personality: An International Journal, 24(2), 143-149.

Pisanski, K., Oleszkiewicz, A., \& Sorokowska, A. (2016). Can blind persons accurately assess body size from the voice? Biology Letters, 12(4), 20160063.

Pisanski, K., Feinberg, D., Oleszkiewicz, A., \& Sorokowska, A. (2017). Voice cues are used in a similar way by blind and sighted adults when assessing women's body size. Scientific Reports, 7(1), 10329.

Re, D. E., DeBruine, L. M., Jones, B. C., \& Perrett, D. I. (2013). Facial cues to perceived height influence leadership choices in simulated war and peace contexts. Evolutionary Psychology, 11(1), 147470491301100109.

Rosch, E., \& Lloyd, B. B. (Eds.). (1978). Cognition and categorization. Hillsdale: Lawrence Erlbaum Associates, Inc.

Rosenthal, R. (1973). The Pygmalion effect lives. Psychology Today, $7(4), 56-63$.

Rosenthal, R., \& Jacobson, L. (1968). Pygmalion in the classroom. The Urban Review, 3(1), 16-20.

Sear, R. (2006). Height and reproductive success. Human Nature, 17(4), 405-418.

Sorokowski, P. (2010). Politicians' estimated height as an indicator of their popularity. European Journal of Social Psychology, 40(7), 1302-1309.

Sorokowski, P., \& Sorokowska, A. (2012). Judgments of sexual attractiveness: A study of the Yali tribe in Papua. Archives of Sexual Behavior, 41(5), 1209-1218.

Sorokowski, P., Sorokowska, A., Fink, B., \& Mberira, M. (2012). Variable preferences for sexual dimorphism in stature (SDS) might not be universal: Data from a semi-nomad population (Himba) in Namibia. Journal of Cross-Cultural Psychology, 43(1), 32-37.

Sorokowski, P., Sabiniewicz, A., Rusicka, I., \& Niemczyk, A. (2014). Czy Kazimierz Wielki był wysoki? Wielkość historyczna władcy jako wyznacznik jego szacowanego wzrostu. Ogrody Nauk i Sztuk, 2014(4), 304-314.

Stulp, G., Buunk, A. P., Verhulst, S., \& Pollet, T. V. (2012). High and mighty: Height increases authority in professional refereeing. Evolutionary Psychology, 10(3), 588-601.

Stulp, G., Buunk, A. P., Verhulst, S., \& Pollet, T. V. (2013). Tall claims? Sense and nonsense about the importance of height of US presidents. The Leadership Quarterly, 24(1), 159-171.

Taki, Y., Hashizume, H., Sassa, Y., Takeuchi, H., Asano, M., Asano, K., Kotozaki, Y., Nouchi, R., Wu, K., Fukuda, H., \& Kawashima, R. (2012). Correlation among body height, intelligence, and brain gray matter volume in healthy children. Neuroimage, 59(2), 1023-1027.

Tanner, J. M. (1966). Galtonian eugenics and the study of growth: The relation of body size, intelligence test score, and social circumstances in children and adults. The Eugenics Review, 58(3), 122-135.

Teasdale, T. W., Owen, D. R., \& Sørensen, T. I. A. (1991). Intelligence and educational level in adult males at the extremes of stature. Human Biology, 63(1), 19-30.

Turrell, G. (2002). Socio-economic position and height in early adulthood. Australian and New Zealand Journal of Public Health, 26(5), 468-472.

Undurraga, E. A., Zebrowitz, L., Eisenberg, D. T. A., Reyes-García, V., Bolivia Study Team, T. A. P. S., \& Godoy, R. A. (2012). The perceived benefits of height: Strength, dominance, social concern, and knowledge among Bolivian native Amazonians. PLoS ONE, 7(5), 1-10.

Wheeler, P. G., Bresnahan, K., Shephard, B. A., Lau, J., \& Balk, E. M. (2004). Short stature and functional impairment: A systematic review. Archives of Pediatrics and Adolescent Medicine, 158, 236-243.

Wiesel, T. N. (1982). The postnatal development of the visual cortex and the influence of environment. Bioscience Reports, 2(6), 351-377.

Wilson, D. M., Hammer, L. T. D., Duncan, P. M., Dornbusch, S. M., Ritter, P. L., Hintz, R. L., Gross, R. T., \& Rosenfeld, R. G. (1968). Growth and intellectual development. Pediatrics, 78, 646-650.

Zou, X., Tam, K. P., Morris, M. W., Lee, S. L., Lau, I. Y. M., \& Chiu, C. Y. (2009). Culture as common sense: Perceived consensus versus personal beliefs as mechanisms of cultural influence. Journal of Personality and Social Psychology, 97, 579-597.

Publisher's note Springer Nature remains neutral with regard to jurisdictional claims in published maps and institutional affiliations. 